\title{
Diferentes extratos aquosos de plantas no tratamento de solo para o controle de Meloidogyne javanica
}

\author{
Different aqueous extracts of plants in soil treatment for Meloidogyne javanica control
}

\section{Mariana Martins Marcondes ${ }^{1 *}$, Rosangela Dallemole-Giaretta ${ }^{2}$, Marielle Martins Marcondes ${ }^{2}$, Silvana Girotto Martins Ferreira ${ }^{1}$ e Cacilda Márcia Duarte Rios Faria ${ }^{1}$}

\author{
Recebido em 12/12/2014 / Aceito em 11/10/2015
}

\section{RESUMO}

O objetivo desse ensaio foi avaliar o efeito de extratos aquosos de Baccharis trimera, Plantago sp., Verbena officinalis e Arctium lappa no controle de Meloidogyne javanica, em casa de vegetação. $\mathrm{O}$ experimento foi montado em vasos plásticos contendo uma mistura solo e areia 2:1 (volume : volume), infestada com 4.000 ovos de $M$. javanica e adicionado $200 \mathrm{~mL}$ dos respectivos extratos. Após sete dias foi transplantada uma muda de tomate em cada vaso. As avaliações do número de galhas e de ovos do nematoide por sistema radicular foram realizadas após 50 dias do transplantio das mudas. Os dados foram submetidos à análise de variância e as médias comparadas pelo teste de Duncan, a $5 \%$ de probabilidade. Nenhum dos tratamentos testados reduziu o número de galhas e de ovos de M. javanica por sistema radicular.

PALAVRAS-CHAVE: Baccharis trimera, Plantago sp., Verbena officinalis, Arctium lappa, nematoide das galhas.

\section{ABSTRACT}

The objective of this study was to evaluate the effect of aqueous extracts of Baccharis trimera, Plantago sp., Verbena officinalis and Arctium lappa on the M. javanica control in the greenhouse. The experiment was performed in plastic pots containing a soil mixture and sand 2:1 (volume: volume), it was infested with 4.000 eggs of Meloidogyne javanica and $200 \mathrm{~mL}$ of the respective aqueous extract was added. After seven days a tomato seedling was transplanted in each pot. The evaluations of the number of galls and eggs of the nematode by root system were performed after 50 days of transplanting the seedlings. The data was subjected to analysis of variance and the means were compared by Duncan test at $5 \%$ probability. None of the tested treatments reduced the number of galls and eggs of M. javanica per root system.

KEYWORDS: Baccharis trimera, Plantago sp., Verbena officinalis, Arctium lappa, root-knot nematode.

\section{INTRODUÇÃO}

Os nematoides formadores de galhas radiculares, pertencentes ao gênero Meloidogyne, constituem o grupo de nematoides com maior importância econômica na agricultura. Diferentes métodos de manejo podem ser utilizados para o controle do nematoide das galhas. O controle químico, empregando-se nematicidas-inseticidas, usualmente é caro e, suas implicações toxicológicas tanto para o meio ambiente quanto para a saúde humana são frequentemente lembradas, visto que tais produtos geralmente são de alta toxicidade (CORBANI 2008). Com isso, métodos alternativos de controle de namatoides têm sido estudados, dentre eles, a utilização de extratos aquosos de plantas, vem apresentando bons resultados no controle de algumas espécies de fitonematoides (COSTA et al. 2001, GARDIANO et al. 2009). Dessa forma, o objetivo do trabalho foi avaliar o efeito dos extratos aquosos de carqueja (Baccharis trimera), tansagem (Plantago sp.), gervão (Verbena officinalis) e bardana (Arctium lappa) no controle de Meloidogyne javanica em plantas de tomate.

\footnotetext{
${ }^{1}$ Universidade Estadual do Centro-Oeste, Guarapuava, PR, Brasil.

${ }^{2}$ Universidade Tecnológica Federal do Paraná, Pato Branco, PR, Brasil.

*Autor para correspondência <mariana.mmarcondes@hotmail.com>.
} 
O experimento foi conduzido no município de Guarapuava - PR, na Universidade Estadual do Centro-Oeste - Unicentro, em casa de vegetação. Utilizou-se o delineamento experimental inteiramente casualizado e foram testados os extratos aquosos de carqueja (Baccharis trimera), tansagem (Plantago sp.), gervão (Verbena officinalis) e bardana (Arctium lappa). Água foi utilizada como tratamento testemunha (apenas água). Foram utilizadas oito repetições por tratamento. Os extratos foram obtidos a partir da infusão de $100 \mathrm{~g}$ de folhas secas das espécies de plantas, obtidas no comércio local, em $100 \mathrm{~mL}$ de água fervente, individualmente, por uma hora. Posteriormente, cada extrato foi filtrado em camada dupla de gaze para utilização no experimento (FERRIS \& ZHENG 1999).

Em sacos plásticos pretos foram colocados separadamente $8 \mathrm{~kg}$ do substrato solo + areia, previamente esterilizados, na proporção de 2:1 (volume : volume), o qual foi infestado com uma suspensão contendo 4.000 ovos de M. javanical $\mathrm{kg}$ substrato e adicionados o total de $200 \mathrm{~mL}$ dos respectivos tratamentos. Em seguida, foram acondicionados em câmara de crescimento a $25{ }^{\circ} \mathrm{C}$, por uma semana. No sétimo dia, o substrato foi colocado em vasos de polipropileno de 1.000 $\mathrm{mL}$ de capacidade e foi transplantada uma muda de tomateiro por vaso. As avaliações foram realizadas aos 50 dias após o transplantio, contando-se o número de galhas e número de ovos por sistema radicular. Os dados foram submetidos à análise de variância e as médias comparadas pelo teste de Duncan, a 5\% de probabilidade pelo programa SISVAR (FERREIRA 2008).
Não foi observada diferença significativa para o número de galhas por sistema radicular entre os tratamentos utilizados neste estudo (Tabela 1). Esses resultados corroboram com os obtidos por MATEUS (2012) que também não observou eficiência na redução do número de galhas por sistema radicular de plantas de tomateiro, para os extratos de gervão e tansagem aplicados via solo, no controle de $M$. javanica. Por outro lado, GARDIANO et al. (2009) ao testarem o extrato aquoso de dez espécies vegetais adicionados ao solo, observaram redução de $65,73 \%$ e $34,35 \%$ no número de galhas por grama de raiz do tomateiro, respectivamente, para os extratos de bardana e carqueja.

Em relação ao número de ovos, todos os extratos testados favoreceram a eclosão dos junvenis de segundo estádio (J2) do nematoide (Tabela 1). Os extratos de bardana, tansagem, gervão e carqueja promoveram um aumento de 108,82\%; 119,05\%; $134,95 \%$ e $218,27 \%$, respectivamente, no número de ovos de $M$. javanica quando comparados ao tratamento testemunha. A redução no número de ovos de $M$. javanica com a adição ao solo do extrato de bardana $(75,85 \%)$ e carqueja $(45,74 \%)$ foi constatado por GARDIANO et al. (2009). Em contra partida, MATEUS (2012) também não encontrou diferenças significativas entre os extratos de gervão e tansagem em relação ao tratamento testemunha para o número de ovos por sistema radicular nos tomateiros. No presente estudo era esperado que o método de extração por infusão, o maior período de permanência do extrato no solo em contato com os ovos dos nematoides antes do transplantio das mudas de tomate e a dose utilizada fossem eficientes no controle deste

Tabela 1 - Número de galhas e de ovos de Meloidogyne javanica por sistema radicular de tomateiros aos 50 dias após o transplantio das mudas.

Table 1 - Number of galls and eggs of Meloidogyne javanica by tomato root system after 50 days of transplanting the seedlings.
Tratamento
Número de galhas
Número de ovos

\begin{tabular}{lllll}
\hline Testemunha & $2.842,4^{\text {ns }}$ & $172.041,7$ & $\mathrm{~b}$ & \\
Bardana & $2.639,6$ & $187.220,8$ & $\mathrm{~b}$ & $\mathrm{a}$ \\
Tansagem & $3.080,5$ & $204.816,7$ & $\mathrm{~b}$ & $\mathrm{a}$ \\
Gervão & $2.731,5$ & $232.175,0$ & $\mathrm{~b}$ & $\mathrm{a}$ \\
Carqueja & $3.581,4$ & $375.509,5$ & & $\mathrm{a}$ \\
\hline
\end{tabular}

Média de oito repetições. Médias seguidas pela mesma letra não diferem entre si pelo Teste de Duncan, a 5 \% de significância. ${ }^{\text {ns }}$ - não significativo. 
fitoparasita. Contudo, as plantas testadas não devem ser descartadas quanto ao seu potencial nematicida, pois, outros métodos de obtenção dos princípios ativos das plantas, assim como outras doses, podem resultar em diferentes resultados.

\section{REFERÊNCIAS}

CORBANI RZ. 2008. Estudo do extrato pirolenhoso biopirol ${ }^{\circledR}$ no manejo de nematóides em cana-de-açúcar, olerícolas e citros em diferentes ambientes. Tese (Doutorado em Agronomia). Jaboticabal: UNESP. 53f.

COSTA MJN et al. 2001. Toxicidade de extratos vegetais e de estercos a Meloidogyne incognita. Summa Phytopathol. 27: 245-250.

FERREIRA DF. 2008. SISVAR. Versão 5.3. Lavras: UFLA. FERRIS H \& ZHENG L. 1999. Plant sources of Chinese herbal remedies: effects on Pratylenchus vulnus and Meloidogyne javanica. J. Nematol. 31: 241-263.

GARDIANO CG et al. 2009. Avaliação de extratos aquosos de várias espécies vegetais, aplicados ao solo, sobre Meloidogyne javanica (Treub, 1885) Chitwood, 1949. Semina Ci. Agrár. 30: 551-556.

MATEUS MAF. 2012 Extratos aquosos de plantas medicinais no controle de nematoides das galhas. Dissertação (Mestrado em Agronomia). Guarapuava: UNICENTRO. 59p. 